\title{
Looking at the Future of Medical Tourism in Asia
}

Somjit Barat, Pennsylvania State University, USA

\begin{abstract}
Despite the popularity of 'medical tourism' (which involves travel to a foreign destination for primarily medical reasons) as a thriving global industry in recent times, a comprehensive model that emphasizes the decision-making process from the patient's perspective is lacking. In the current paper, the author develops a framework based on the protection motivation theory and designs a robust model, that focuses on how prospective Western patients intend to seek medical treatment in Asian countries. Through an extensive review of extant literature, the author presents five propositions involving key elements of the theoretical framework and makes insightful projections about the future of this flourishing industry. The author believes that this research will immensely benefit the hospitality industry and healthcare practitioners and patients.
\end{abstract}

\section{KEYWORDS}

Health Tourism, India, Medical Tourism, Protection Motivation Theory

\section{INTRODUCTION}

Medical or health tourism involves a trip to a foreign country with the primary purpose of seeking medical treatment. The patient may undergo a medical, dental, holistic improvement or cosmetic procedure, and the trip typically involves some level of sightseeing or entertainment activities in addition to the 'treatment'.

On one hand, we are witnessing escalating healthcare costs and long waiting times for medical procedures in Western Countries (Japan, Australian subcontinent, US, Canada and Western Europe). Concomitantly, with the increasing availability of healthcare resources in non-Western countries, more and more Westerners are availing of this global phenomenon called 'medical tourism'. Rising insurance costs, population growth, and urbanization in Western countries on one hand, and cheaper and less cumbersome international travel, healthcare quality and accreditation, shorter waiting times for surgery, availability of highly trained health professionals in non-Western countries on the other, have catapulted medical tourism to an exploding industry (NASDAQ OMX's News Release, 2019; Medhekar et al., 2018; MT1, 2016).

The market is expected to grow at a compounded annual growth rate (CAGR) of almost $16 \%$ during the 2019-2025 period, with the US and UK topping the list of medical tourists, while Asian (and to some extent, Latin American) countries appear to be the most popular medical tourism destinations 
(Bookman and Bookman, 2007; Crooks et al., 2017). Dentistry, cardiovascular procedures, oncology, and in-vitro fertilization (IVF) procedures seem to be the most sought-after procedures for medical tourists (NASDAQ OMX's News Release, 2019). Globally, more than 21 million people travelled abroad to seek medical care of which, 1.4million were Americans, who travelled for cancer, heartby-pass, dental crowns, cosmetic surgery and other short-stay outpatient procedures. Thailand itself hosted 2.4million medical tourists in 2016 (Medhekar et al. 2018). Similarly, experts predict that the Indian medical tourism market will be worth US $\$ 8$ billion by 2020 (Thornton, 2015), and expect it to grow by 30 per cent annually (Naik \& Lal, 2013). Thus, there is no question that medical tourism has flourished considerably over the recent years and keeps changing at a rapid pace. Consequently, this topic calls for further research.

It is no surprise, that there exits considerable exploration in this field. A quick search of literature in Google Scholar featuring the words 'medical tourism' in the title yielded almost 13000 results (post-2015). The literature can be categorized under the following broad topics: antecedents (demandoriented or 'push' factors), destination- or supply-oriented (pull factors), scale development, industry trends, consequences-based, negative impacts, challenges and future of medical tourism (A de la Hoz-Correa et al., 2018; Fetscherin \& Stephano, 2016; Han \& Hyun, 2015; Lee \& Fernando, 2015; Suess et al., 2018; Wongkit \& McKercher, 2016).

However, extant research on medical tourism mostly ignores the importance of the individual's threat perception and coping mechanisms, and the roles that these perceptions play in influencing the individual's decision whether to seek treatment in the first place. In other words, extant studies leave a gaping hole in medical tourism research. What is also lacking, according to the author's finding, is a concerted effort to build a robust model that also takes into consideration the supply-oriented or 'pull' factors of medical tourism.

This is where the author feels that the Protection Motivation Theory (PMT) can play an important role in helping us better understand if and why patients seek medical treatment, because PMT addresses both the threat perception as well as coping mechanism of the patient into account. To the best of the author's knowledge few, if any, research has looked at medical tourism from the PMT lens. A search on Google Scholar using the keywords 'medical tourism' and 'protection motivation theory' yielded only one result (Seow et al., 2018). Therefore, the current analysis will address a lacuna in extant research.

It is neither feasible nor necessary to assess all antecedents of medical tourism within the ambit of the current paper. Instead, the author analyzes how some of the most salient factors influence the individual's threat assessment from the ailment i.e. price differential, reputation of location, facility and physician and referral/word of mouth about destination. Through an extensive review of extant literature, the author presents five propositions involving key elements of the theoretical framework and makes insightful projections about the future of this flourishing industry.

The author believes that this research will immensely benefit the hospitality industry, healthcare practitioners and patients alike by putting the 'patient first'. More specifically, from a customer service point of view, this research can help us better appreciate how patients make a holistic decision as to if, when, where and how to receive medical services abroad, and gives credence to their threat perception and coping mechanism. Thus, healthcare providers and medical practitioners can market their goods and services more effectively and efficiently. As a result, more marketing dollars will be put to the best use. In addition, this line of research can potentially generate new ideas and discussion among practitioners and academics.

The next step in the author's research process is to collect data from medical tourists from Asian countries, fine tune the propositions into testable hypotheses, analyze patient responses, and subject the hypotheses to a test of significance based on such responses.

The paper is organized as follows: the introduction is followed by a review of the current state of medical tourism in India and Thailand; the next section introduces PMT, its relevance, the conceptual framework, while the subsequent section introduces the reader to the propositions designed for the 
current study. The penultimate section of this article is devoted towards potential concerns and implications, while the final section provides limitations and plans for further research.

\section{MEDICAL TOURISM IN ASIA}

India, Malaysia, Thailand, Indonesia and Singapore are the main medical tourist destinations in Asia. However, this research focuses on India and Thailand due to their overwhelming share in the Asian medical tourism industry.

According to the Government of India, more than 370,000 people travelled to India in 2017 on an M- (medical) visa (Medhekar et al., 2019). Realizing the potential of medical tourism both from health as well as economic perspectives, the Indian Government stepped up its efforts. Several initiatives (introducing the M-visa (medical), e-visa, visa-on-arrival, declaring India as the "Global Health Destination' as part of its recent fiver-year planning process (CII-Mckinsey, 2013; India Healthcare Tourism, 2019)) have led to India being ranked as the fifth most popular medical tourism destination in the world, and number two in Asia (MTI, 2016).

The government has provided added incentives in the form of reduced taxes on import of medical equipment and permit for 100\% foreign direct investment (FDI) in the medical tourism sector for both goods and services. The government has also made prime land available at subsidized rates to encourage set up of medical facilities (Gupta, 2008). Some of the most sought-after procedures for medical tourists in India include cosmetic and weight-loss procedures, cardiac and heart surgery, orthopedics, transplant, ophthalmology, wellness prevention and alternative medicine (FICCI, 2016). Indian medical treatment imbibes both traditional and modern medicine. Consequently, patients have a choice of allopathy, homeopathy, Ayurveda, Unani, Yoga etc. (Medhekar et al., 2019).

Such proactive measures have led to some impressive results for the Indian medical tourism sector: over the last five years, the number of medical tourists to India has been growing at a rate of 30\% (The Economic Times, 2016). Moreover, the medical tourism industry is expected to reach $\$ 7-8$ bn by 2020 (FICCI medical value travel report, 2016). The Indian health sector as a whole is expected to be worth $\$ 280$ billion by 2020 and has been growing at a CAGR of $16 \%$ since 2011 . India received almost 290 million USD worth of foreign direct investment (FDI) in the healthcare sector.

In terms of inflow of medical tourists to India, neighboring countries like Burma, Bangladesh, Sri Lanka, Maldives and the like occupy the lion's share. However, realizing the potential beyond the immediate vicinity, the Indian Government has drawn a strategic plan to attract patients from the US, Gulf countries, Western Europe and China over the medium term, while focusing on weight loss surgery, spine surgery and fertility treatment in terms of specialty (FICCI, 2016). To sum up, it can be concluded that India sits on the cusp of a major explosion in medical tourism that can reach half way across the world over the next decade.

Another popular destination for medical tourists is Thailand, which welcomed 3.5 million foreign medical tourists and spent upwards of four billion euros on healthcare in 2016 (Mooter, 2017). It is estimated that foreign patients earn between 40-55 percent of the private hospitals' revenue. Most medical tourists to Thailand hail from Japan, USA, South Asia, UK, Middle East, and ASEAN (Association of Southeast Asian Nations) countries, and the country specializes in cosmetic and sex change surgery. Research suggests that as of 2006, medical tourism has not impacted the domestic scenario of Thailand - rather, experienced physicians in urban areas are moving from teaching hospitals to private hospitals to care for foreign medical tourists. In this regard, Thailand has a competitive advantage over its compatriots, because it boasts of almost $80 \%$ doctors with specialty training (Pocock $\&$ Phua, 2011). Similar to that of India, the Thai Government also proactively marketed the country as the 'go-to' destination through its 'Amazing Thailand' initiative, whereby it promoted the country as the ultimate abode for spas, hospitals and herbal products (Russell 2006). Bumrungrad International Hospital is one of the pioneers of medical tourism in Thailand and is one of only 33 hospitals that target exclusively foreign nationals for treatment (Sukin and Kurz 2006). In some ways, Thailand is 
odd because very few of its 700 governmental and 300 private hospitals are actually equipped for medical tourism (Cohen, 2008).

Similar to the Bumrungrad International Hospital, the Bangkok Hospital Group has also been expanding rapidly to increase its footprint in the medical tourism industry. The entrance to its flagship facility in Bangkok resembles a luxury hotel, featuring marble walls, upholstered seating areas and state-of-the-art relaxation and entertainment facilities. Such opulent characteristics of a 'hospital' are designed to relieve the patient of the tension and trauma associated with medical treatment (Siripunyawit, 2005).

The above discussion, therefore, establishes beyond doubt that the Asia-Pac countries, spearheaded by India and Thailand, have taken the onus on themselves to aggressively seek medical tourists from across the globe. While such measures have already begun to place these countries on the frontier of medical tourism, some unavoidable side effects have also set in, mainly in term of the 'social cost' to the local population (discussed in detail in a subsequent section of this paper). There is hardly any doubt that the countries are competing among themselves for a share of the limited pie. As of now, given that medical tourists have ample choices, the next section focuses on how patients narrow down such choices to make their final selection for receiving medical treatment.

\section{PROTECTION MOTIVATION THEORY}

The PMT is based on an individuals' perception of threat from any ailment and his/her ability to respond to such threat. Specifically, the antecedents of an individual's response are comprised of perception of 'severity' of the threat (how severe the ailment is) and how 'vulnerable' the individual feels from the threat (will I contract the ailment?). On the other hand, the outcomes of such decision-making process by the individual can be categorized as 'response-efficacy' (ability to follow recommendations to counter the threat) and 'self-efficacy' (belief in one's ability to execute recommendations successfully), according to Hall (2014) and Rogers (1983).

According to PMT, the individual's coping mechanism in response to the threat of ailment shapes his/her intention to act (whether to seek medical treatment). Naturally, everyone's perception of severity of the threat from an ailment is different based on his/her personality, hearsay, access to internal and external information as well as how the individual interprets such information. Likewise, how likely the individual is to get impacted by the threat varies with the individual's risk assessment and risk tolerance. Typically, most individuals can withstand a nominal dose of risk, especially if he/she were rewarded in the past for taking risks. If the person perceives the impact of the threat to be low, they will consider themselves less vulnerable and as such, are less likely to react. However, when their perceived threat from the ailment reaches a certain threshold level, the individual is likely to take some retaliatory action (i.e. how to counter the threat from the ailment).

Once the threat of contracting the ailment exceeds the individuals' threshold level, the response mechanism sets in, which is identified as a two-part response as per PMT. The individual first assesses whether it is at all possible to counter the threat by following a certain recommended course of action (is there any treatment available for the ailment?). In other words, the individual tries to decide if there is an efficient response to the threat available in the first place (response-efficacy)? If and when the individual identifies a feasible course of action, then the individual attempts to assess his/her own capability (self-efficacy) in following the recommended course of action that will cure the ailment, should he/she contract it. As the PMT argues, the individual's perception of self-efficacy influences his/her intention to take proactive steps in response to the threat, i.e. if the threat is severe enough and the individual perceives that they can mitigate the negative consequences of the threat by taking corrective action, then they will intend to seek medical treatment abroad.

Finally, an individual's intention to behave in a certain manner has been found to be a robust predictor of his/her actual behavior (refer to the Theory of Planned Behavior by Ajzen (1985, 1991 \& 2002; see Figure 1)). Interestingly, research suggest that a little over half of individuals with positive 
Figure 1. Protection motivation theory as applied to medical tourism

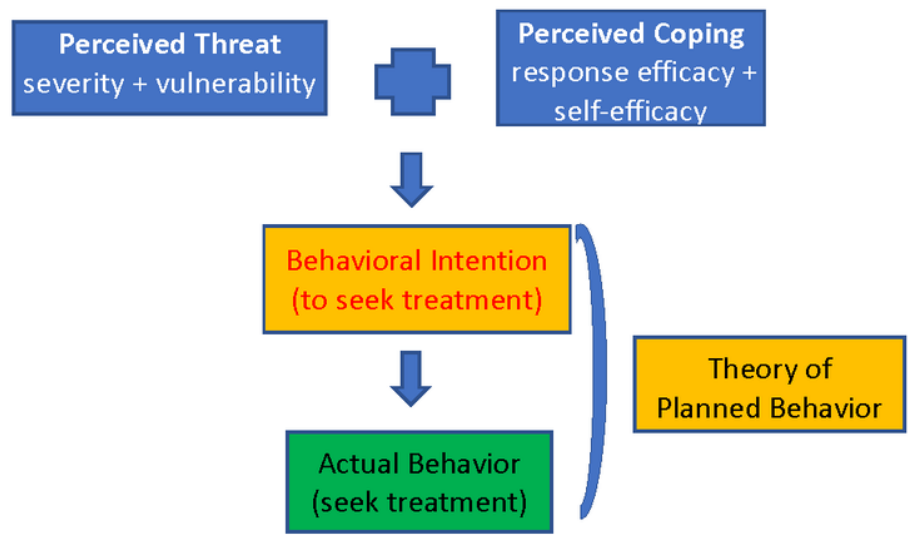

intention to take any action successfully convert such intention into actual behavior in the health field (Prestwich et al., 2015 and Sheeran, et al., 2005). As such, we focus on how the supply-based antecedents (pull-factors) of medical tourism influence the individual's intention to seek treatment abroad, which will provide us with the appropriate background to introduce our propositions for research in the next section.

Figure 2. Theory of planned behavior

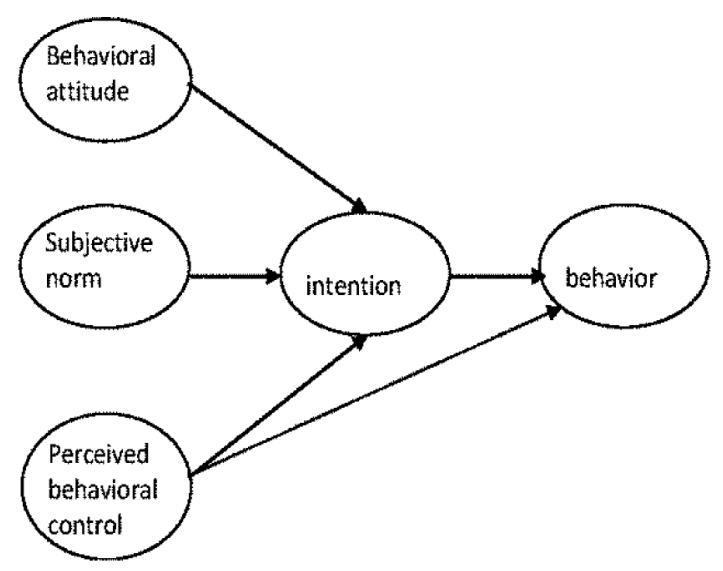

Adapted from Conner, M., \& Sparks, P. (2005). Theory of planned behavior and health behavior. Predicting health behavior, 2(1), 121-162.

\section{OPERATIONAL MODEL}

Several antecedents have given prominence to medical tourism industry in the Asia-Pacific countries. The most prominent factors are price differential, reputation of physician, reputation of location, word of mouth and reputation of facility.

Price Differential: According to the World Health Organization (WHO), U.S. healthcare spending is estimated to be $19.3 \%$ of its GDP by 2019 (Truffer et al., 2010). Not only is healthcare cost 
skyrocketing in the Western world, but so is the cost of retaining insurance, which results in an increasing number of people being without insurance coverage. For example, an estimated 27.5 million Americans (8.5\% of the population) did not have any health insurance at some point of time in 2018 (Census, US, 2019). Moreover, even for those who are insured, often the insurance companies cover a miniscule percentage or none of certain expensive medical procedures.

Concomitantly, availability of a large, trained and skilled pool of personnel in the healthcare industry of Asian countries have created a robust and cheaper healthcare hospitality infrastructure that has increasingly gained attention of potential patients from the West. For example, a single heartvalve replacement procedure would cost about $\$ 275,000$ in the US (of which, less than 50\% would be covered by insurance). The same procedure would cost about $\$ 9,500$ in the US and $\$ 10,500$ in Thailand.

Healthcare-like most other 'normal goods', tends to follow the Law of Demand i.e. lower the price, higher the demand for the product and vice versa (for an economics perspective, see Evans \& Popova, 2017 and Paraje, 2016). As such, it is no surprise that patients from Western countries are easily attracted to Asian countries for medical treatment. While there have been some references to price differential and perceived price reasonableness (Han \& Hyun, 2015) as mediating factors in medical tourism, no research seems to highlight how such factors might influence the individual's intention to seek treatment. As such, the author proposes that higher the price differential of medical procedures between two countries, higher the intention of the individual to seek medical tourism, leading to our first proposition as follows:

P1: Higher the price differential of medical procedures between two countries, higher the intention of the individual to seek medical tourism in the more affordable country

Reputation of Medical Facility: Unlike most other services, the healthcare industry and its customers (i.e. potential patients) adhere extra importance to the reputation of the service provider. Such vetting process includes (but is not necessarily limited to) credentials such as patient feedback, malpractice complaints, lawsuits and the like. Research shows that potential medical tourists feel more comfortable about seeking treatment at a facility of repute compared to one that is obscure or of questionable reputation.

To this end, some Asian governments have undertaken proactive steps to bring their infrastructure and credentials to internationally accepted standards and benchmarks, one of the foremost among them being the Joint Commission International (JCI) accreditation of medical facilities. Research suggests that such accreditation has a positive impact on the perception of expected quality of medical service by foreign patients (Gowrisankaran \& Town, 2003). For example, India, arguably one of largest hosts among Asian medical tourists, has as many as $28 \mathrm{JCI}$-accredited medical facilities (Top Hospitals, 2017). Moreover, medical tourists perceive that the risks of medical or surgical errors and/or post-operative infection are minimal at facilities that are JCI certified (Canaway et al., 2017; Horowitz et al., 2007). In other words, while, there is ample research to suggest that reputation of medical facility is a strong antecedent of medical tourism 'destination image', no research seems to highlight how such reputation might influence the individual's intention to seek treatment, which motivates our second proposition as follows:

P2: Higher the reputation of the facility delivering the service, higher the intention of the individual to seek medical treatment in a foreign country.

Reputation of Physician: Reputation precedes a person, more so for physicians than for most other service providers, simply because physicians deal with human lives. Reputation is established through the physician's credentials (e.g. type of certification, degree earned, the degree-granting institute, reputation of affiliated medical facility, years of experience, success rate and feedback 
from patients and colleagues. Positive reputation not only reflects competence (Han and Hyun, 2015; Nikbin et al., 2019) but also builds trust with patients. High trust (Coulter \& Coulter, 2002; Wirtz \& Mattila, 2004), in turn, results in the patient's increased satisfaction and eventual loyalty towards the physician.

An attending physician's reputation, knowledge and expertise also has a direct bearing on his/her ability to explain the nature of the disease, the course of treatment, desirable outcomes as well as the potential risks involves, if any. Such perceived qualities of the physician are regarded highly by the patient and puts the latter at ease, resulting in repeat visit (Chiu et al., 2012; Lankton et al., 2010). As indicated earlier in the PMT, words and acts of confidence and assurance from the physician can positively influence the patient's coping mechanism. As such, the author envisions a positive correlation between physician reputation and intention to seek treatment, hence the next proposition, which states:

P3: Higher the reputation of the physician, higher the intention of the individual to seek medical treatment from that physician.

Reputation of Location: 'Medical tourism' is as much about 'tourism' as it is about seeking a 'treatment'. In other words, the popularity, prestige and image of the destination play an equally important role in influencing the individual's intention to seek treatment at a foreign location, especially when the patient has multiple options available. Consequently, Asian countries have gone to great lengths to preserve and enhance their images in the eyes of their Western clients (Medhekar et al., 2019; Nikbin et al., 2019). Some of the critical image components include political stability (Fetscherin et al., 2016), law and order (Temenos et al., 2016), terrorist activities (Andrews, 2016), cleanliness (Shukla et al., 2019), medical malpractice (Cohen, 2015), visa restrictions (Jain et al., 2018; Ile et al., 2017; Sankar, 2019) and transportation system (Rydback et al., 2018). Given that these are more 'visible' factors from the traveler's perspective, there exists considerable research on how these factors influence prospective clients' evaluation of destinations accordingly. Broadly speaking, it comes as no surprise that individuals will give high importance to the reputation of the physician and of the facility when it comes to receiving treatment at foreign location. Such intention stems from the individual's basic need for safety and security (health, employment, property, family and social stability) as suggested by Maslow's hierarchy of needs model (Maslow, 1943; see Appendix).

Nonetheless, the research appears to be more geared towards 'tourism' in general and less towards 'medical tourism', with almost no evidence of focus on how such factors influence the customer's intention to seek treatment. As such, this motivates our fourth proposition as follows:

P4: Higher the reputation of the foreign location, higher the intention of the individual to seek medical treatment at that location.

Referral/Recommendation: It is frequently suggested that 'word of mouth' (WOM) is the best and only free marketing tool available at the service provider's disposal, and how it positively influences a person's choice mechanism when it comes to medical tourism (Doosti et al., 2016; Mohammad et al., 2019; Hassan \& Hemdi, 2016). Positive WOM leads to brand loyalty (Karjaluoto et al., 2016), building of trust and confidence (Goodman, 2019; Barreda et al., 2015), repeat purchase and increase in market share, especially in the tourism industry (SuarezAlvarez et al., 2019). In fact, research also suggests that customers always give more credence to WOM and social media exchange from acquaintances and customer reviews than to industry reports, salespersons and company advertisements (Berger \& Schwartz., 2011; Berger, 2016; Lindsey-Mullikin \& Borin, 2017; Whitler, 2014; Woods, 2016). A medical tourist who has a good experience overseas, typically comes back home and shares his/her positive outcome with friends 
and relatives. This often leads to chain reaction and may positively influence the intentions of the patient's acquaintances to seek a medical procedure in that country. Perhaps, this behavior can be attributed to the role of subjective norms on the individual's behavioral intention i.e. how the individual's friends and acquaintances influence his/her attitude towards (the outcomes of) an action (i.e. seeking treatment abroad), according to the Theory of Reasoned Action (Fishbein \& Ajzen, 1977). This line of reasoning motivates our fifth and last proposition as (see Figure 3):

P5: Higher the referral/recommendation of the location, higher the intention of the individual to seek medical treatment at that location.

\section{Figure 3. Model of propositions}

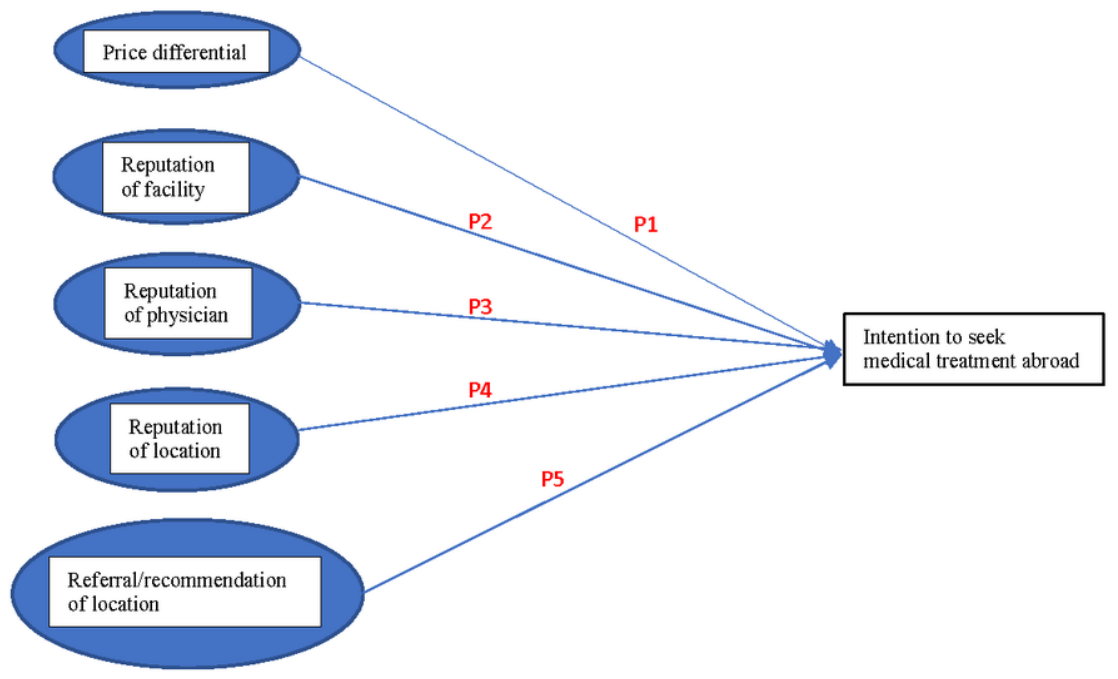

\section{POTENTIAL CONCERNS, IMPLICATIONS AND SUGGESTED SOLUTIONS}

An epidemic outbreak is not very uncommon these days, such as the Ebola virus, avian flu, HIV/ AIDS (for a more comprehensive list see MPH online at https://www.mphonline.org/worst-pandemicsin-history/). While such epidemics can not be completely eliminated, being able to control such occurrences becomes more challenging because of the popularity of medical tourism, which is characterized by frequent travel across borders and consequent interchange of physicians, patients, personnel and medical equipment (WHO, 2015, 2016; Cooper et al., 2015).

As the current pandemic has revealed, political leaning, privacy issues, foreign policies and economic power often take precedence over scientific facts. This has resulted in misguided policy decisions and consequent loss of hundreds and thousands of lives, and of foreign tourists getting engulfed in the quagmire (Amouzagar et al., 2016). One way to minimize (if not avoid) such policy discrepancy across countries and inconvenience to medical tourists is to follow a central authority such as the World Health Organization. Failure to follow science and medical professionals should be reprimanded and prosecuted to the fullest extent as permissible by law, where applicable. In other words, the central authority and medical experts (instead of political leaders) should have the prerogative in making policy decisions in pandemic situations such as this.

In some cases, medical tourists might be caught off-guard due to sudden political unrest in the destination (for example, the coup d'etat of September 2006 in Thailand, one of the largest Asian medical tourism destinations; see Myands \& Fuller, 2006); or due to a global pandemic such as the COVID-19 Thousands of medical tourists are caught unaware because of overnight travel restrictions, 
border closures, movement limitations, social distancing and sanitation requirements. This causes unfathomable misery for the medical tourist not just in the foreign country but also for those lucky few who are able to return to their home countries (Al-Shamsi et al., 2020). For example, when medical tourists were able to return to their home country, the local doctors did not have the medical reports, test results, treatment history, not to mention the differences in treatment protocol and lack of access to the patient's medical history. Consequently, it is important that prospective tourists review international travel warnings of their respective countries before departure (US Department of State, for example). One possible remedy to avoid such problems is to standardize medical procedures and protocols, including (but not limited to) medical tests, reports, filing and sharing of information among participating countries. Thanks to the Internet, patients and medical caregivers should not have to worry about social distancing when it comes to dissemination of information.

Some authors have also expressed concerns about surrogacy, child trafficking (Cooper et al., 2015), and human organ extraction rackets (Caulfield et al., 2016; Columb, 2018; Pascalev et al., 2016) as possible side effects of medical tourism. A 2007 report (apparently still the most recent) suggested that China, Pakistan and the Philippines were the three largest organ-exporting countries (Shimazono, 2007). While travelling to a foreign country may be the only available option for many patients desperately in need of an organ, lack of paperwork, protocols, informed consent, age of the donor are some of the issues that raise a red flag. Both the home country and the tourist country need to have established, written laws that must be communicated in no uncertain terms to local healthcare providers as well as medical tourists. It is equally important to enforce the same, and violators must be prosecuted and awarded exemplary punishment to discourage the occurrence and perpetration of such illegal and unethical activities.

Another concern about medical tourism is that, the host country often channelizes significant volume of resources towards medical tourists at the cost of the local population. Consequently it starts to affect the local patients, many of whom had already limited health resources to start with. Dearth of physicians in Asian countries makes this a severe issue. For example, India has only 0.8 physicians per 1,000 people compared to 2.6 in the US (World Bank, 2020). Hospitals geared towards medical tourists operate on a for-profit basis, so they naturally attract the best medical talent, thereby further shrinking the already scarce resources available to the common people in the destination country (referred to as the 'social cost' of medical tourism by Burkett (2007)). To counter such problem, the host country government needs to have a robust policy framework in place such that resources can be allocated in a more balanced manner. Such measures can not help the host country build and improve an advanced medical tourism industry but also gain the support of its own citizens.

Another concern is that of regulation and ethics. While most Asian medical tourism destinations boast of world class service, lack of an international accreditation body to vet all such procedures, systems, operations and surgeries often makes such claims suspect. For example, does the patient have any recourse in case of dispute regarding health records transfer, malpractice, operative procedures or post-operative recovery? In some instances (reproductive health, in-vitro ferritization techniques, cosmetic surgeries, euthanasia etc.), procedures that are either banned or under trial in Western countries are often legally offered in Asian destinations (Law, 2006). Thailand, for example, specializes in sex-change procedures, which is banned in many Western countries.

\section{LIMITATIONS AND PLANS FOR FURTHER RESEARCH}

As long as there is wide price differential in the cost of services and insurance premiums between Western countries and their Asian counterparts, medical tourism will survive and thrive. It is in the best interest of both who seek and those who offer treatment, to work collaboratively on addressing some of the concerns discussed in the literature, especially with regard to accreditation, standardization and certification (Rydback \& Haider, 2018; Adabi et al., 2016; Sharma et al., 2017; Momeni et al., 2018). Therefore, the medical fraternity needs to address the concerns. Thus, the host countries will 
be able to leverage their unique advantages to benefit their local patients and economies. With more standardized procedures, streamlining of paperwork and documentation, and international accreditation in place, more countries can cater to the increasing demand of medical tourism and potentially reduce the burden on a handful of countries.

The author's next step is to collect data from the most prominent medical tourism facilities, such as the Apollo Hospitals Enterprise Limited and Fortis Healthcare Limited (both predominant in India) and Bumrungrad International Hospital in Thailand. The author will collect customer feedback on why they chose to receive treatment at those locations. The instrument for data collection will be based on those used by Fetscherin et al., (2016); Wongkit et al., (2016) and Das et al., (2016).

The instrument will also include specific items related to the purpose of travel, which can potentially help elicit issues such as organ harvesting, surrogacy, spurious medication etc. However, given the sensitive nature of such issues, respondents may be reluctant to divulge such information, even though the author will take utmost care to preserve the anonymity and confidentiality of the same.

Once the data is analyzed, the author will conduct a factor analysis in order to confirm the existence of the five 'factors' identified in the current study, and make necessary changes, if required, to convert those 'propositions' into testable hypotheses. The final stage will be to conduct regressions analyses with the intention to avail medical treatment as the dependent variable and each of the five factors as independent variables. Depending on whether the null hypotheses are rejected or not, the author will provide further avenues for advanced research.

One limitation of this approach is the author's ability to collect data that will be usable and reliable. For this purpose, the author will use his professional contacts in the focal countries (India and Thailand - the two most popular medical tourism destinations in Asia). If required, the author will purchase medical tourist databases to send out surveys.

The second challenge is to have the instrument translated appropriately into the local language (Hindi and Thai respectively for India and Thailand) for which, translation and back translation need to be conducted (Epstein et al., 2015; Prabhumoye et al., 2018).

Third, since the author plans to collect data only from Asian countries, it remains to be seen if and how the results can be generalized to non-Asian countries as well. The author surmises that there may not be significant differences between Asian and non-Asian medical tourism destinations. Despite the limitations, the author has adopted appropriate steps such that most of these hurdles can be minimized, and sincerely hopes that this research will germinate new interest in the field of medical tourism. 


\section{REFERENCES}

de la Hoz-Correa, A., Muñoz-Leiva, F., \& Bakucz, M. (2018). Past themes and future trends in medical tourism research: A co-word analysis. Tourism Management, 65, 200-211. doi:10.1016/j.tourman.2017.10.001

Adabi, K., Stern, C. S., Colasante, C., Weichman, K. E., Garfein, E. S., \& Tepper, O. M. (2016). Medical tourism and its impact on plastic surgery in the United States. Plastic and Reconstructive Surgery. Global Open, 4(9, Suppl).

Ajzen, I. (1985). From intentions to actions: A theory of planned behavior. In Action control (pp. 11-39). Springer. doi:10.1007/978-3-642-69746-3_2

Ajzen, I. (1991). The theory of planned behavior. Organizational Behavior and Human Decision Processes, 50(2), 179-211. doi:10.1016/0749-5978(91)90020-T

Ajzen, I. (2002). Perceived behavioral control, self-efficacy, locus of control, and the theory of planned behavior 1. Journal of Applied Social Psychology, 32(4), 665-683. doi:10.1111/j.1559-1816.2002.tb00236.x

Al-Shamsi, H. O., Abu-Gheida, I., Rana, S. K., Nijhawan, N., Abdulsamad, A. S., Alrawi, S., Abuhaleeqa, M., Almansoori, T. M., Alkasab, T., Aleassa, E. M., \& McManus, M. C. (2020). Challenges for cancer patients returning home during SARS-COV-19 pandemic after medical tourism-a consensus report by the Emirates oncology task force. BMC Cancer, 20(1), 1-10. doi:10.1186/s12885-020-07115-6 PMID:32650756

Amouzagar, S., Mojaradi, Z., Izanloo, A., Beikzadeh, S., \& Milani, M. (2016). Qualitative examination of health tourism and its challenges. International Journal of Travel Medicine and Global Health, 4(3), 88-91. doi:10.21859/ijtmgh-040304

Andrews, H. (Ed.). (2016). Tourism and violence. Routledge. doi:10.4324/9781315550763

Barreda, A. A., Bilgihan, A., \& Kageyama, Y. (2015). The role of trust in creating positive word of mouth and behavioral intentions: The case of online social networks. Journal of Relationship Marketing, 14(1), 16-36. do i: $10.1080 / 15332667.2015 .1006002$

Berger, J., \& Schwartz, E. M. (2011). What drives immediate and ongoing word of mouth? JMR, Journal of Marketing Research, 48(5), 869-880. doi:10.1509/jmkr.48.5.869

Berger, J. (2016). Contagious: Why things catch on. Simon and Schuster.

Bookman, M. Z., \& Bookman, K. R. (2007). Medical tourism in developing countries. Palgrave Macmillan. doi: $10.1057 / 9780230605657$

Burkett, L. (2007). Medical tourism: Concerns, benefits, and the American legal perspective. Journal of Legal Medicine, 28(2), 223-245. doi:10.1080/01947640701357763 PMID:17558794

Canaway, R., Bismark, M., Dunt, D., \& Kelahar, M. (2017). Medical directors' perspectives on strengthening hospital quality and safety. Journal of Health Organization and Management, 31(7/8), 696-712. doi:10.1108/ JHOM-05-2017-0109 PMID:29187081

Caulfield, T., Duijst, W., Bos, M., Chassis, I., Codreanu, I., Danovitch, G., Gill, J., Ivanovski, N., \& Shin, M. (2016). Trafficking in human beings for the purpose of organ removal and the ethical and legal obligations of healthcare providers. Transplantation Direct, 2(2), e60. doi:10.1097/TXD.0000000000000566 PMID:27500253

Census, United States. (2019). Health insurance coverage in the United States: 2018. Retrieved October 4, 2019 from https://www.census.gov/library/publications/2019/demo/p60-267.html

Chiu, C., Hsu, M., Lai, H., \& Chang, C. (2012). Re-examining the influence of trust on online repeat purchase intention: the moderating role of habit and its antecedents. Decision Support Systems, 53(4), 835-845.

CII-Mckinsey. (2013). Travel and tourism sector: Potential, opportunities and enabling framework for sustainable growth. CII-Mckinsey.

Cohen, E. C. E. (2008). Medical tourism in Thailand. AU-GSB E-Journal, l(1). 
Cohen, I. G. (2015). Regulating bodies across borders: Medical tourism for services legal in the home and destination country: Legal and ethical issues. In Bodies Across Borders: The Global Circulation of Body Parts, Medical Tourists and Professionals. Ashgate.

Columb, S. (2018). Organ trafficking: Transplant tourism and trafficking in persons for the removal of organs. The SAGE Handbook of Human Trafficking and Modern Day Slavery, 155.

Cooper, M., Vafadari, K., \& Hieda, M. (Eds.). (2015). Current issues and emerging trends in medical tourism. IGI Global. doi:10.4018/978-1-4666-8574-1

Coulter, K. S., \& Coulter, R. A. (2002). Determinants of trust in a service provider: The moderating role of length of relationship. Journal of Services Marketing, 16(1), 35-50. doi:10.1108/08876040210419406

Crooks, V. A., Ormongd, M., \& Jin, K. N. (2017). Reflections on 'medical tourism' from the 2016 global healthcare policy and management forum. BMC Proceedings, 11(8), 1-4. doi:10.1186/s12919-017-0075-8 PMID:28813541

Das, G., \& Mukherjee, S. (2016). A measure of medical tourism destination brand equity. International Journal of Pharmaceutical and Healthcare Marketing, 10(1), 104-128. doi:10.1108/IJPHM-04-2015-0015

Doosti, S., Jalilvand, M. R., Asadi, A., Khazaei Pool, J., \& Mehrani Adl, P. (2016). Analyzing the influence of electronic word of mouth on visit intention: The mediating role of tourists' attitude and city image. International Journal of Tourism Cities, 2(2), 137-148. doi:10.1108/IJTC-12-2015-0031

Epstein, J., Osborne, R. H., Elsworth, G. R., Beaton, D. E., \& Guillemin, F. (2015). Cross-cultural adaptation of the Health Education Impact Questionnaire: Experimental study showed expert committee, not back-translation, added value. Journal of Clinical Epidemiology, 68(4), 360-369. doi:10.1016/j.jclinepi.2013.07.013 PMID:24084448

Evans, D. K., \& Popova, A. (2017). Cash transfers and temptation goods. Economic Development and Cultural Change, 65(2), 189-221. doi:10.1086/689575

Fetscherin, M., \& Stephano, R. M. (2016). The medical tourism index: Scale development and validation. Tourism Management, 52, 539-556. doi:10.1016/j.tourman.2015.08.010

FICCI. (2016). Medical value transport report. Accessed at http://www.ficci.in/Medical-Value-Travel-Report.pdf

Fishbein, M., \& Ajzen, I. (1977). Belief, attitude, intention, and behavior: An introduction to theory and research. Addison-Wesley Publishing Company.

Goodman, J. (2019). Strategic customer service: Managing the customer experience to increase positive word of mouth, build loyalty, and maximize profits. Amacom.

Gowrisankaran, G., \& Town, R. (2003). Competition, payers, and hospital quality. Health Services Research, 38(6), 1403-1421. doi:10.1111/j.1475-6773.2003.00185.x PMID:14727780

Gupta, A. (2008). Medical tourism in India: Winners and losers. Indian Journal of Medical Ethics, 5(1), 4-5. doi:10.20529/IJME.2008.002 PMID:18630244

Hall, C. M. (2014). Tourism and social marketing. Routledge. doi:10.4324/9780203854259

Han, H., \& Hyun, S. S. (2015). Customer retention in the medical tourism industry: Impact of quality, satisfaction, trust, and price reasonableness. Tourism Management, 46, 20-29. doi:10.1016/j.tourman.2014.06.003

Hassan, N. A., \& Hemdi, M. A. (2016). The influence of destination image on medical tourist's intention for future destination choice. Environment-Behaviour Proceedings Journal, 1(1), 178-185. doi:10.21834/e-bpj.v1i1.214

Horowitz, M. D., Rosensweig, J. A., \& Jones, C. A. (2007). Medical tourism: Globalization of the healthcare. Medscape General Medicine, 9(4), 33-45. PMID:18311383

Ile, F. L., \& Țigu, G. (2017, July). Medical tourism market trends-an exploratory research. In Proceedings of the International Conference on Business Excellence (Vol. 11, No. 1, pp. 1111-1121). De Gruyter Open. doi:10.1515/picbe-2017-0114

India Healthcare Tourism. (2019). Accessed at http://www.indiahealthcaretourism.com 
Jain, V., \& Ajmera, P. (2018). Modelling the factors affecting Indian medical tourism sector using interpretive structural modeling. Benchmarking, 25(5), 1461-1479. doi:10.1108/BIJ-03-2017-0045

Karjaluoto, H., Munnukka, J., \& Kiuru, K. (2016). Brand love and positive word of mouth: The moderating effects of experience and price. Journal of Product and Brand Management, 25(6), 527-537. doi:10.1108/ JPBM-03-2015-0834

Lankton, N. K., Wilson, E. V., \& Mao, E. (2010). Antecedents and determinants of information technology habit. Information Management, 47, 300-307.

Law, Marc T. (2006). How do regulators regulate? Enforcement of the pure food and drugs Act, 22 J.L. ECON. \& $O R G, 459$.

Lee, H. K., \& Fernando, Y. (2015). The antecedents and outcomes of the medical tourism supply chain. Tourism Management, 46, 148-157. doi:10.1016/j.tourman.2014.06.014

Lindsey-Mullikin, J., \& Borin, N. (2017). Why strategy is key for successful social media sales. Business Horizons, 60(4), 473-482. doi:10.1016/j.bushor.2017.03.005

Maslow, A. H. (1943). Dynamics of personality organization. I. Psychological Review, 50(5), 514-539. doi: $10.1037 / \mathrm{h} 0062222$

Medhekar, A., Wong, H. Y., \& Hall, J. E. (2019). Factors influencing inbound medical travel to India. Journal of Health Organization and Management, 33(2), 155-172. doi:10.1108/JHOM-08-2018-0234 PMID:30950309

Mohamad, W. N., Omar, A., \& Kassim, N. M. (2019). The effect of understanding companion's needs, companion's satisfaction, companion's delight towards behavioural intention in Malaysia medical tourism. Global Business and Management Research, 11(2).

Momeni, K., Janati, A., Imani, A., \& Khodayari-Zarnaq, R. (2018). Barriers to the development of medical tourism in East Azerbaijan province, Iran: A qualitative study. Tourism Management, 69, 307-316. doi:10.1016/j. tourman.2018.05.007

Mooter, B. V. (2017). Medical Tourism in Asia-Pacific Growing Rapidly. Brinknews. Accessed at https://www. brinknews.com/medical-tourism-in-asia-pacific-growing-rapidly/\#targetText=In\%202016\%2C\%20between $\% 20$ 105\%20and,in\%20the\%20coming\%20three\%20years.\&targetText=In\%202016\%2C\%20the \%20medical\%20 tourism, $17 \% 20$ billion\%20uros\%20in\%20revenues

OnlineM. P. H. (2019). Accessed at https://www.mphonline.org/worst-pandemics-in-history/

MTI. (2016). Medical Tourism Index Asian Region. Available at: www.medicaltourismindex.com/overview/ destination-ranking/

Myands, S. \& Fuller, T. (2006, Sept. 20). With Premier at U.N., Thai Military Stages Coup. N.Y. Times, p. A1.

Naik, N. T. K., \& Lal, B. S. (2013). Economic analysis of Indian medical tourism: International healthcare destination. International Journal of Business Management. Economics and Information Technology, 5(2), 259-277.

NASDAQ OMX's News Release. (2019). Global medical tourism market drivers, restraints, opportunities, trends, and forecast up to 2025. NASDAQ OMX's News Release Distribution Channel. Retrieved from http:// ezaccess.libraries.psu.edu/login?url=https://search-proquest-com.ezaccess.libraries.psu.edu/docview/222587 4967? accountid $=13158$

Nikbin, D., Batouei, A., Iranmanesh, M., Kim, K., \& Hyun, S. S. (2019). Hospital prestige in medical tourism: Empirical evidence from Malaysia. Journal of Travel \& Tourism Marketing, 36(4), 521-535. doi:10.1080/105 48408.2019.1582397

Paraje, G. (2016). The effect of price and socio-economic level on the consumption of sugar-sweetened beverages (SSB): The case of Ecuador. PLoS One, 11(3), e0152260. doi:10.1371/journal.pone.0152260 PMID:27028608

Pascalev, A., De Jong, Ambagtsheer, F., Lundin, S., Gunnarson, M., Bystrom, I., Linde, van B., Ivanovski, \& Weimer, W. (2016). Trafficking in human beings for the purpose of organ removal: a comprehensive literature review. In Trafficking in human beings for the purpose of organ removal: Results and recommendations. Lengerich: Pabst Science Publishers. 
Pocock, N. S., \& Phua, K. H. (2011). Medical tourism and policy implications for health systems: A conceptual framework from a comparative study of Thailand, Singapore and Malaysia. Globalization and Health, 7(1), 12. doi:10.1186/1744-8603-7-12 PMID:21539751

Prabhumoye, S., Tsvetkov, Y., Black, A. W., \& Salakhutdinov, R. (2018). Style transfer through multilingual and feedback-based back-translation. arXiv preprint arXiv:1809.06284

Prestwich, A., Sheeran, P., Webb, T. L., \& Gollwitzer, P. (2015). Implementation intentions. In M. Connor \& P. Norman (Eds.), Predicting Health Behavior (3rd ed., pp. 321-357). McGraw-Hill.

Rogers, R. (1983). Cognitive and psychological processes in fear appeals and attitude change: A revised theory of protection motivation. In Social Psychology: A Sourcebook. New York: Guilford Press.

Rydback, M., \& Hyder, A. S. (2018). Customization in medical tourism in the Philippines. International Journal of Pharmaceutical and Healthcare Marketing, 12(4), 486-500. doi:10.1108/IJPHM-07-2017-0035

Russell, C. (2006, Apr. 27). A Kinder Cut. Bangkok Post, 1.

Sankar, P. (2019). Medical tourism in India: Issues, opportunities and designing strategies for growth and development. Sociology of Medical Tourism, 227.

Seow, A. N., Choong, Y. O., \& Chan, L. M. (2018). What influences the behavioral intention in medical tourism? A threat and coping perspective. Global Business and Management Research, 10(3).

Sharma, N., Jain, A. K., Gupta, P. K., \& Sharma, S. D. (2017). Review of adoption of disruptive innovative practices in medical tourism in India. Asian Journal of Pharmaceutical Research and Health Care, 9(3), 112-123. doi:10.18311/ajprhc/2017/15497

Sheeran, P., Milne, S. E., Webb, T. L., \& Gollwitzer, P. M. (2005). Implementation intentions. In M. Conner \& P. Norman (Eds.), Predicting Health Behavior (pp. 276-323). Open University Press.

Shimazono, Y. (2007). The state of the international organ trade: A provisional picture based on integration of available information. Bulletin of the World Health Organization, 85(12), 901-980. doi:10.2471/BLT.06.039370 PMID: 18278256

Shukla, R., Singh, M., \& Saxena, S. (2019). Consumer perception of hospitality services in JCI accredited hospitals at Delhi-NCR: An exploratory research on growth of medical tourism. Humanities \& Social Sciences Reviews.

Siripunyawit, S. (2005). Never missing a beat. The Bangkok Post, 26(December), B11.

Suárez-Álvarez, L., Río-Lanza, A. B. D., Vázquez-Casielles, R., \& Díaz-Martín, A. M. (2019). Switching barriers in online travel agencies: The impact on positive word of mouth. Tourism Analysis, 24(2), 213-225. doi:10.37 27/108354219X15525055915545

Suess, C., Baloglu, S., \& Busser, J. A. (2018). Perceived impacts of medical tourism development on community wellbeing. Tourism Management, 69, 232-245. doi:10.1016/j.tourman.2018.06.006

Sukin, K., \& Kurz, S. (2006, May 21). Lucrative healing touch. The Nation, p. 1A, 3A.

Temenos, C., \& Johnston, R. (2016). Constructing the liberal health care consumer online: A content analysis of Canadian medical tourism and harm reduction service provider websites. In Place, Health, and Diversity (pp. 163-182). Routledge.

The Economic Times. (2016). Government approves new visa policy to attract foreigners, boost trade. The Economic Times. Available at: http://economictimes.indiatimes.com/nri/visa-and-immigration/governmentapproves-new-visa-policy-to-attract-foreigners-boost trade/articleshow/55722289

Thornton, G. (2015). Indian medical tourism industry to touch $\$ 8$ billion by 2020. The Economic Times.

Top Hospitals in India 2017 - JCI. (n.d.). https://www.frankit.in/blog/top-hospitals-in-india-2017-jci-accredited

Truffer, C., Keehan, S., Smith, S., Cylus, J., Sisko, A., Poisal, J., Lizonitz, J., \& Clemens, K. M. (2010). Health spending projections through 2019: The recession's impact continues. Health Affairs, 29(3), 522-529. doi:10.1377/ hlthaff.2009.1074 PMID:20133357 
Wongkit, M., \& McKercher, B. (2016). Desired attributes of medical treatment and medical service providers: A case study of medical tourism in Thailand. Journal of Travel \& Tourism Marketing, 33(1), 14-27. doi:10.10 80/10548408.2015.1024911

Whitler, K. A. (2014). Why word of mouth marketing is the most important social media. Forbes. Accessed at https://www.forbes.com/sites/kimberlywhitler/2014/07/17/why-word-of-mouth-marketing-is-the-most-importantsocial-media/\#521ca80754a8

Wirtz, J., \& Mattila, A. S. (2004). Consumer responses to compensation, speed of recovery and apology after a service failure. International Journal of Service Industry Management, 15(2), 150-166. doi:10.1108/09564230410532484

Wongkit, M., \& McKercher, B. (2016). Desired attributes of medical treatment and medical service providers: A case study of medical tourism in Thailand. Journal of Travel \& Tourism Marketing, 33(1), 14-27. doi:10.10 80/10548408.2015.1024911

Woods, S. (2016). \# Sponsored: The emergence of influencer marketing. Academic Press.

World Bank. (2020). Physicians (per 1,000 people); World Health Organization's Global Health Workforce Statistics. OECD. Accessed at https://data.worldbank.org/indicator/SH.MED.PHYS.ZS

World Health Organization. (2015). Action agenda for antimicrobial resistance in the Western Pacific Region. WHO.

World Health Organization. (2016). National action for global change on antimicrobial resistance. WHO Regional Office for the Western Pacific.

Somjit Barat (PhD in Marketing, University of North Texas) is an Associate Professor of Business at Penn State, Mont Alto (Pennsylvania, USA). He teaches Principles of Marketing, Personal Selling, Consumer Behavior, Retailing, Sports Marketing, Marketing Research and Global Marketing. His research involves promotions using grocery coupons, customer satisfaction in banking, ethics of drug trials and Bollywood, among other areas of interest. He has published in a variety of journals such as Alliance Journal of Business Research, Journal of Transnational Management, Journal for the Advancement of Marketing Education, Journal of Product and Brand Management etc. Dr. Barat has also presented papers at different conferences organized by the Academy of Marketing Science, American Marketing Association, International Academy of Business and Economics, Society for Marketing Advances etc. Outside of academics, Dr. Barat is actively involved in global education and study abroad initiatives that promote diversity in education and collaboration. 